\title{
Analysis of Voltage Unbalance due to Single-Phase Dispersed Generation Systems in Three-Phase Low-Voltage Distribution Feeders
}

\author{
Wen-Chih Yang, Kuo-Fen Liu \\ Department of Electrical Engineering \\ Taipei City University of Science and Technology \\ Taiwan, R.O.C.
}

\author{
Chen-Hong Lin, Zih-Yuan Lin \\ Institute of Mechatronic Engineering \\ Taipei City University of Science and Technology \\ Taiwan, R.O.C.
}

\begin{abstract}
The major purpose of this paper is to analyze the voltage unbalance situations of a three-phase low-voltage distribution feeder with single-phase dispersed generation systems. The simulation tool used in this paper is OpenDSS. There are three factors that affect the voltage unbalance of a three-phase low-voltage distribution feeder, connection point, connection phase and power generation, which are considered in this paper. The simulation results show that the connection point, connection phase and power generation of the singlephase dispersed generation systems will affect the original voltage unbalance of the low-voltage distribution feeders. If the connection points and phases of single-phase dispersed generation systems can be arranged appropriately in advance, the voltage unbalance of the low-voltage distribution feeders will be improved.
\end{abstract}

Keywords-Dispersed generation system, distribution feeder, OpenDSS, voltage unbalance.

\section{INTRODUCTION}

In recent years, the greenhouse effect of the earth has become increasingly obvious, climate change has become severely, and the frequency of natural disasters has increased. Affected by this, the concept of dispersed generation (DG) attracts more and more attention from people and has gradually become a trend in the power generation industry [1].

DG is usually renewable energy power generation, such as wind power, solar power or hydropower generation [2]. Large-scale renewable energy power generation systems are usually interconnected with transmission systems or highvoltage power distribution systems. Conversely, small-scale renewable energy power generation systems are interconnected with low-voltage distribution systems [3]. In Taiwan, renewable energy generation systems with a capacity of less than $100 \mathrm{~kW}$ are only allowed to be interconnected to low-voltage distribution feeders.

A low-voltage power distribution system consists of transformers, switches, distribution feeders and protection equipment. Low-voltage distribution systems supply electric power to their users by the distribution feeders. The distribution feeders of low-voltage distribution systems have a three-phase structure, but the single-phase loads usually exit in them, so three-phase voltage unbalance problems arise [4,5]. Today, more and more small-scale single-phase dispersed generation systems (DGSs) are integrated into low-voltage distribution systems. Under such circumstances, does the voltage unbalance problem of the three-phase low-voltage distribution feeder become more serious? It is really interesting.

In order to realize the problem described above, a typical three-phase low-voltage distribution system was employed as a sample system in this research. The sample system interconnected with a DGS. The simulation software, OpenDSS, was adopted to simulate the sample system. Simulation results have been reorganized and presented in this paper. They are analyzed and discussed in detail according to the three factors that affect the voltage unbalance of a threephase low-voltage distribution feeder. The results shown in this paper will be beneficial to the operation and maintenance of three-phase low-voltage distribution systems.

\section{THE SAMPLE SYSTEM}

Fig. 1 shows the structure of the sample system. The major components of the sample system are a three-phase distribution transformer, a three-phase breaker and a threephase distribution feeder. The three-phase distribution feeder is called as the sample feeder in this paper. Its structure is three-phase four-wire scheme. Therefore, it consists of three supply conductors and one neutral conductor. For simplicity, the neutral conductor is not shown in Fig. 1.

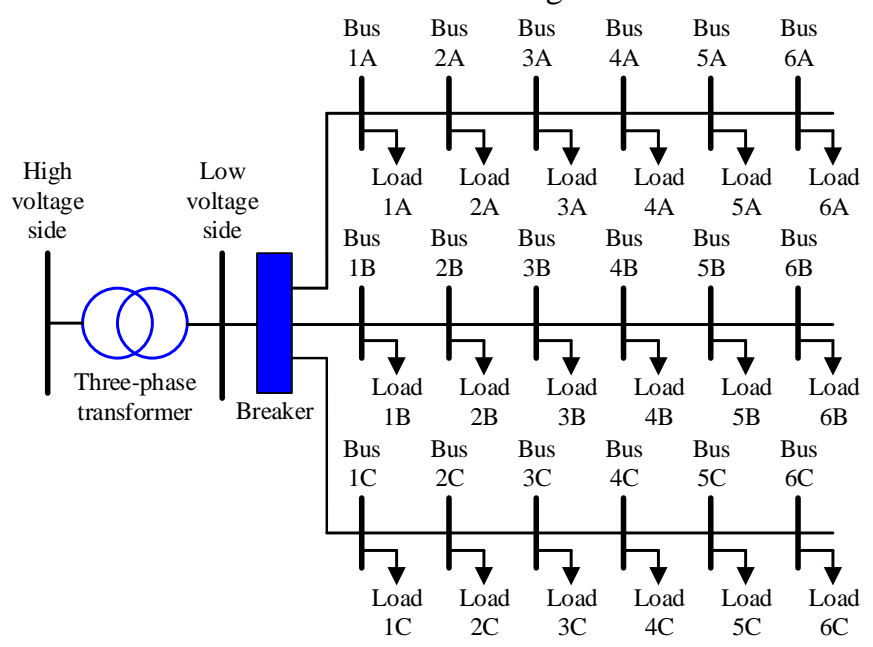

Fig. 1. The structure of the sample system employed in this paper.

The sample feeder is $60 \mathrm{~m}$ long. Six virtual buses are placed on the sample feeder. The interval between two adjacent buses is $10 \mathrm{~m}$. The six virtual buses are numbered 1 
to 6 , where $\mathrm{A}, \mathrm{B}$, and $\mathrm{C}$ are represented as phases. Each bus connects with a load.

The maximum generating capacity of the DGS is $10 \mathrm{~kW}$. The interconnection point and phase of the DGS depend on the research scenarios, so the DGS is not shown in Fig. 1. The parameters of the distribution transformer and the distribution feeder in the sample system are shown below. The load of each bus are shown in Table I.

Distribution transformer:

- Rating capacity : $150 \mathrm{kVA}$

- Winding connection : Delta - Grounded wye

- $\quad$ Rating voltage : $11.4 \mathrm{kV} / 380-220 \mathrm{~V}$

- Winding impedance : $0.0176+\mathrm{j} 0.025 \mathrm{pu}$

Distribution feeder:

- Length : $60 \mathrm{~m}$

- Diameter : $125 \mathrm{~mm} 2$

- Impedance : $0.1842+\mathrm{j} 0.0982 \Omega / \mathrm{km}$

TABLE I THE LOAD OF EACH BUS IN THE SAMPLE SYSTEM

\begin{tabular}{|c|c|c|c|c|c|c|}
\hline $\begin{array}{c}\text { Bus } \\
\text { phase }\end{array}$ & \multicolumn{2}{|c|}{ A } & \multicolumn{2}{c|}{ B } & \multicolumn{2}{c|}{ C } \\
\hline $\begin{array}{c}\text { Bus } \\
\text { number }\end{array}$ & $\begin{array}{c}\text { Load } \\
(\boldsymbol{k} \text { VA })\end{array}$ & $\begin{array}{c}\text { Power } \\
\text { factor }\end{array}$ & $\begin{array}{c}\text { Load } \\
(\boldsymbol{k V A})\end{array}$ & $\begin{array}{c}\text { Power } \\
\text { factor }\end{array}$ & $\begin{array}{c}\text { Load } \\
(\boldsymbol{k V A})\end{array}$ & $\begin{array}{c}\text { Power } \\
\text { factor }\end{array}$ \\
\hline 1 & 4 & 1.0 & 5 & 1.0 & 8 & 1.0 \\
\hline 2 & 4 & 1.0 & 5 & 1.0 & 8 & 1.0 \\
\hline 3 & 4 & 1.0 & 5 & 1.0 & 8 & 1.0 \\
\hline 4 & 4 & 1.0 & 5 & 1.0 & 8 & 1.0 \\
\hline 5 & 4 & 1.0 & 5 & 1.0 & 8 & 1.0 \\
\hline 6 & 4 & 1.0 & 5 & 1.0 & 8 & 1.0 \\
\hline
\end{tabular}

\section{FACTORS AFFECTING VOLTAGE UNBALANCE}

When DGSs are interconnected with a low voltage distribution system, the original voltage unbalance of the low voltage distribution system is affected [6]. There are three major factors affecting the voltage unbalance of low-voltage distribution systems, namely the interconnection point, interconnection phase, and power generation. The three factors are explained below.

\section{A. Interconnection Point}

The interconnection point is where the DGS is interconnected with a low-voltage distribution feeder. The types of low-voltage distribution feeders in Taiwan are all radial. After a DGS is interconnected with a low-voltage distribution system, it will inject electric power into the connected low-voltage distribution feeder. In this way, the magnitude and direction of the power flow in the low-voltage distribution feeder will be changed, so that the voltage profile of the low-voltage distribution feeder changes, and the threephase voltage unbalance will also change.

\section{B. Interconnection Phase}

In Taiwan, the three-phase low-voltage distribution system has a three-phase four-wire structure. The three-phase distribution feeder of the three-phase low-voltage distribution system consists of three supply conductors and one neutral conductor. The single phase DGS is only connected between one of the supply conductors and the neutral wire. When the DGS outputs electric power, only the voltage profile of the connected supply conductor is changed, so the original threephase voltage unbalance of the low-voltage distribution feeder is also changed.

\section{Power Generation}

The voltage drop $\mathrm{V}_{\mathrm{d}}$ and magnitude $\mathrm{V}_{\mathrm{m}}$ of the three-phase low-voltage distribution feeder are determined by (1) and (2), where Is is the current flowing in the supply conductor, $\mathrm{Z}$ is the unit impedance of the supply conductor, 1 is the length of the supply conductor, and $\mathrm{V}_{\mathrm{s}}$ is the voltage on the secondary side of the transformer. When a DGS is interconnected to a three-phase low-voltage distribution feeder, its power generation will affect the magnitude and direction of the current flowing in the connected supply conductor [7]. This will affect the three-phase voltage unbalance of the lowvoltage distribution feeder. The greater the power generation of the DGS, the greater the impact on the three-phase voltage unbalance of the low-voltage distribution feeder.

$$
\begin{aligned}
& V_{d}=I_{s} \times Z \times l \\
& V_{m}=V_{s}-V_{d}
\end{aligned}
$$

\section{SIMULATION RESULTS}

In order to analyze the effect of a single-phase DGS on the voltage unbalance of a three-phase low-voltage distribution feeder, 10 simulation scenarios have been carried out by this research. The definitions of the 10 simulation scenarios and simulation results will be described and discussed in the following subsections according to the three factors stated in section III.

\section{A. Interconnection Point}

A GDS may be connected to any bus of a low-voltage distribution feeder. The interconnection point of a GDS is different, the effect on the voltage unbalance of the connected low-voltage distribution feeder is different. In this research, 4 simulation scenarios namely S0, S1, S2 and S3 have been carried out to present this effect. The 4 simulation scenarios are described as follows. The feeder voltage simulation results are shown in Figs. 2 to 5 and the voltage unbalance ratios (VURs) of the sample feeder are shown in Fig. 6. The VUR is defined in (3).

S0: No DGS connects with the sample feeder.

S1: A DGS connects with the phase A of the bus 6 of the sample feeder and output $10 \mathrm{~kW}$ of active power.

S2: A DGS connects with the phase A of the bus 3 of the sample feeder and output $10 \mathrm{~kW}$ of active power.

S3: A DGS connects with the phase A of the bus 1 of the sample feeder and output 10kW of active power.

$$
V U R=\left(\operatorname{Max} .\left(V_{A}, V_{B}, V_{C}\right)-\operatorname{Min} .\left(V_{A}, V_{B}, V_{C}\right)\right) /\left(V_{A}+V_{B}+V_{C}\right) / 3
$$

Where the $V_{A}, V_{B}$ and $V_{C}$ are the phase voltages of a bus on the sample feeder. Max. means to get the maximum value. Min. means to take the minimum value. 


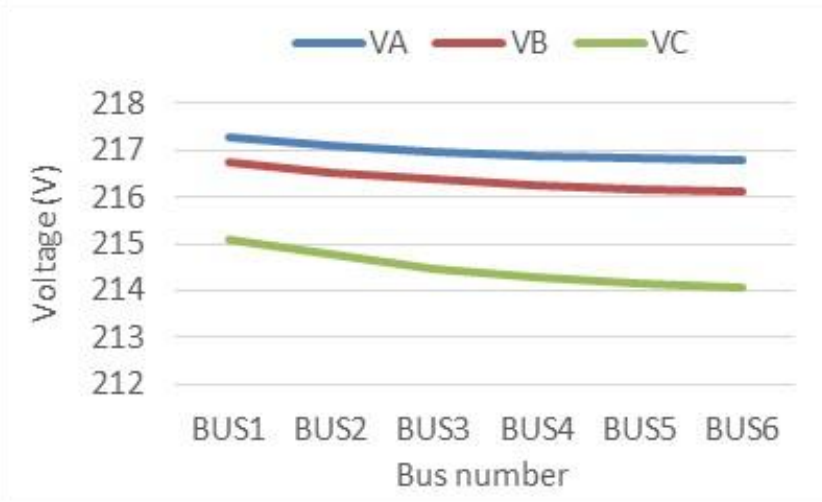

Fig. 2. The voltage profiles of the sample feeder in scenario S0.

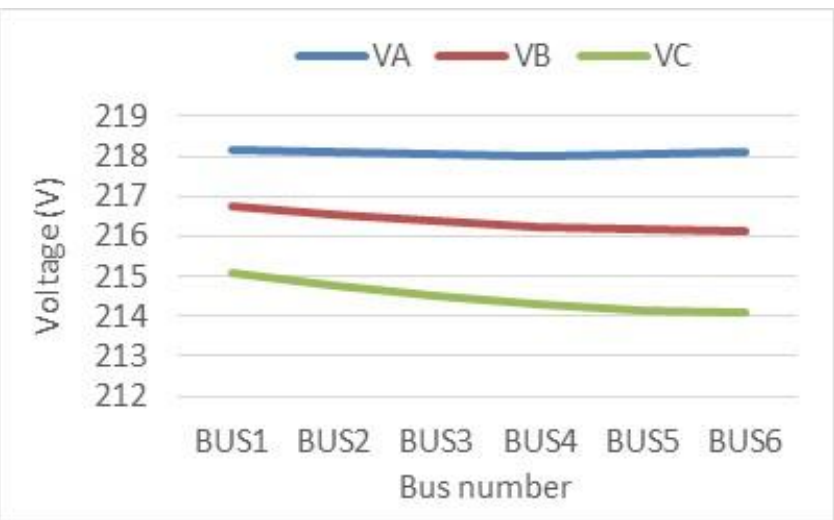

Fig. 3. The voltage profiles of the sample feeder in scenario S1.

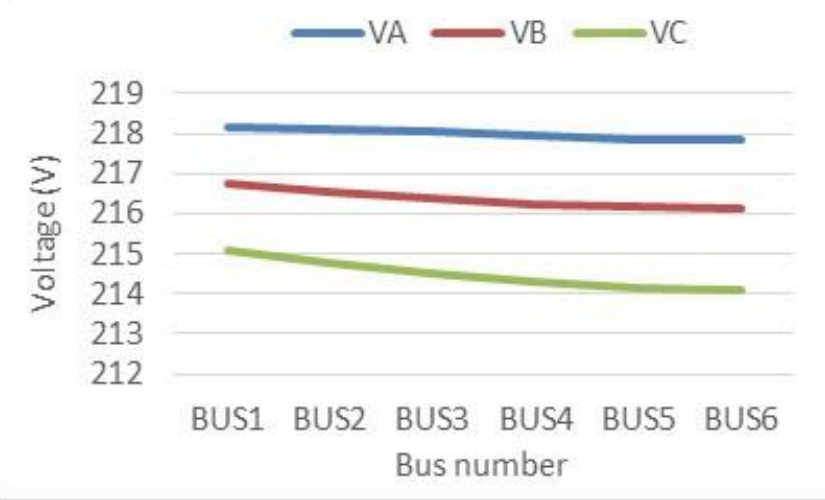

Fig. 4. The voltage profiles of the sample feeder in scenario S2.

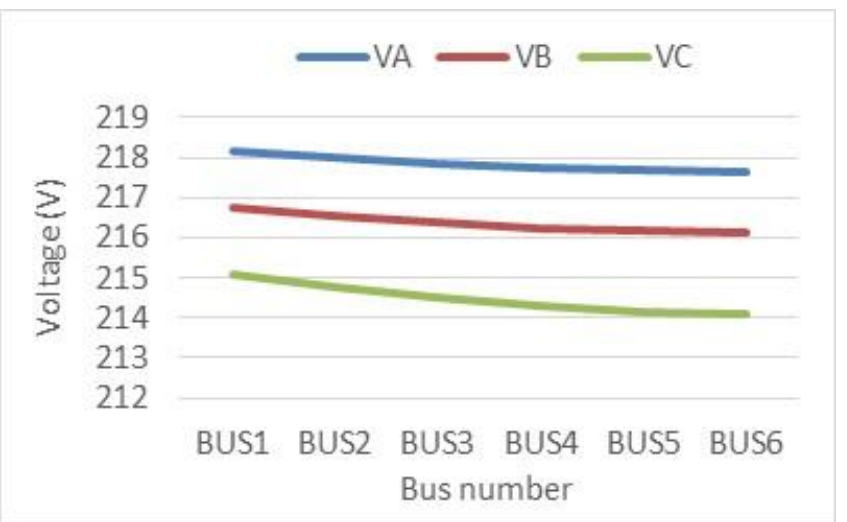

Fig. 5. The voltage profiles of the sample feeder in scenario S3.

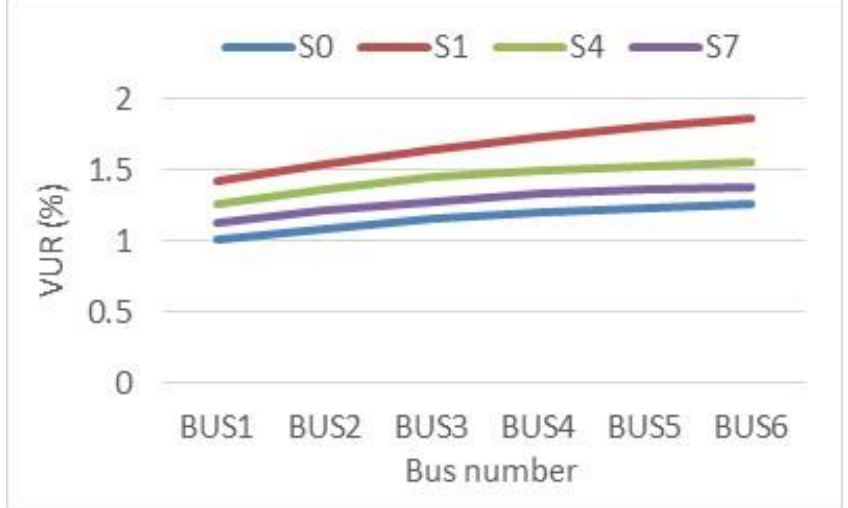

Fig. 6. The VURs of the sample feeder in scenario S0 to S3.

The simulation results in Fig. 6 show that the change of a DGS's interconnection point does affect the voltage unbalance of the connected low-voltage distribution feeder. The closer the interconnection point of a DGS is to the end of the connected low-voltage distribution feeder, the greater the effect on the voltage unbalance of the connected low-voltage distribution feeder.

\section{B. Interconnection Phase}

For a three-phase low-voltage distribution system, its distribution feeder has three phases: A, B and C. A singlephase GDS can be connected to any phase of a low-voltage distribution feeder. The interconnection phase of a GDS is different, the effect on the voltage unbalance of the connected low-voltage distribution feeder is different. In this research, 4 simulation scenarios namely S0, S4, S5 and S6 have been carried out to present this effect. The 4 simulation scenarios are described as follows. The feeder voltage simulation results are shown in Figs. 2 and 7 to 9 and the VURs of the sample feeder are shown in Fig. 10.

S0: No DGS connects with the sample feeder.

S4: A single-phase DGS connects with the phase A of the bus 6 of the sample feeder and output $10 \mathrm{~kW}$ of active power.

S5: A single-phase DGS connects with the phase B of the bus 6 of the sample feeder and output $10 \mathrm{~kW}$ of active power.

S6: A single-phase DGS connects with the phase C of the bus 6 of the sample feeder and output $10 \mathrm{~kW}$ of active power.

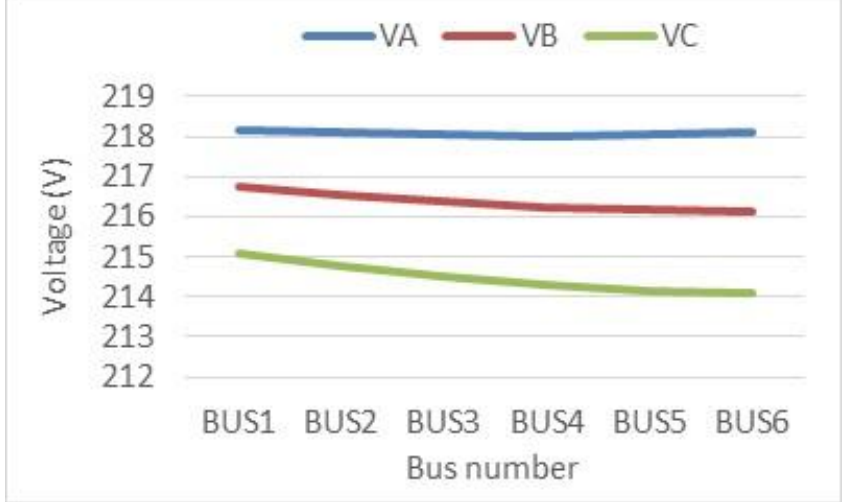

Fig. 7. The voltage profiles of the sample feeder in scenario $\mathrm{S} 4$. 


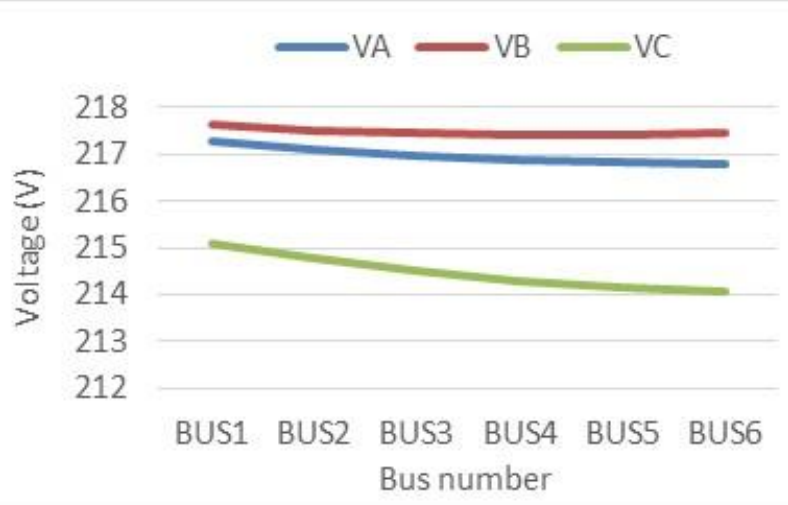

Fig. 8. The voltage profiles of the sample feeder in scenario S5.

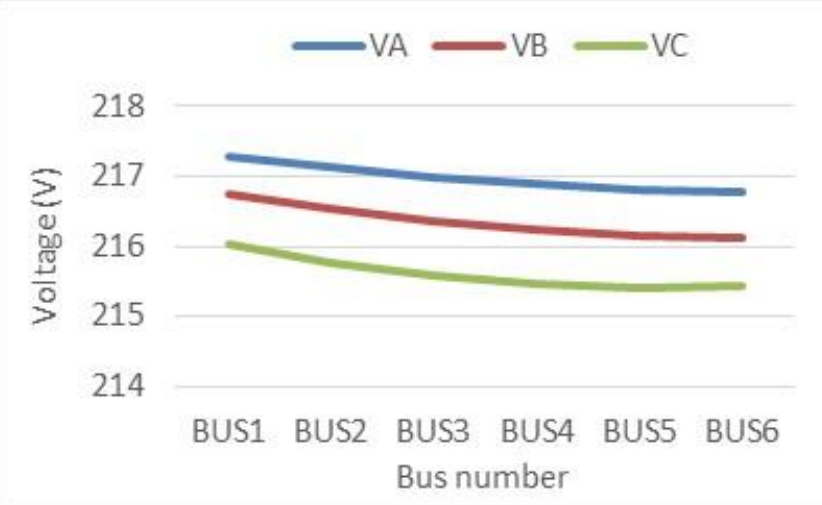

Fig. 9. The voltage profiles of the sample feeder in scenario S6.

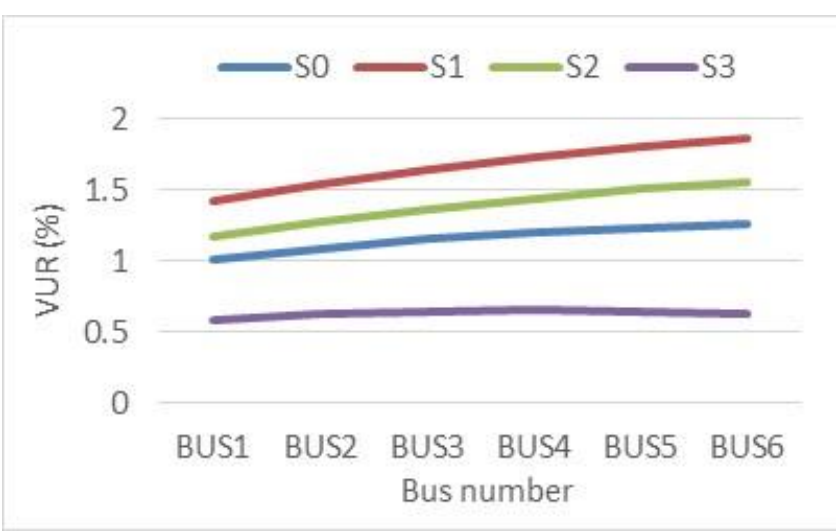

Fig. 10. The VURs of the sample feeder in scenario S0 and S4 to S6.

The simulation results in Fig. 10 show that the change of a DGS's interconnection phase affect the voltage unbalance of the connected low-voltage distribution feeder largely. In the four simulation scenarios, the largest VUR occurs at scenario S4, while the smallest VUR occurs at scenario S6. The major reason is that the load of phase A of the sample feeder is lighter than the phase $\mathrm{C}$. The simulation results in Fig. 10 show that DGSs should be connected to the phase with a heavy load of a low-voltage distribution feeder. In this way the effect of the interconnection of DGSs on the voltage unbalance of the three-phase low-voltage distribution system can be reduced effectively.

\section{Power Generation}

When a DGS is connected to a low-voltage distribution feeder, it will inject electric power into the connected distribution feeder. The power generation of the DGS directly affects the voltage profiles and the voltage unbalance of the connected distribution feeder. In this research, 4 simulation scenarios namely S0, S7, S8 and S9 have been carried out to present this effect. The 4 simulation scenarios are also described as follows. The feeder voltage simulation results are shown in Figs. 2 and 11 to 13 and the VURs of the sample feeder are shown in Fig. 14.

S0: No DGS connects with the sample feeder.

S7: A single-phase DGS connects with the phase C of the bus 6 of the sample feeder and output 10kW of active power.

S8: A single-phase DGS connects with the phase C of the bus 6 of the sample feeder and output $6 \mathrm{~kW}$ of active power.

S9: A single-phase DGS connects with the phase C of the bus 6 of the sample feeder and output $3 \mathrm{~kW}$ of active power.

The simulation results in Fig. 14 show that the variation of a DGS's power generation affect the voltage unbalance of the connected low-voltage distribution feeder. If the DGS is connected to the phase with a light load, the greater the DGS output power, the greater the effect on the voltage unbalance of the connected distribution feeder. Conversely, if the DGS is connected to the phase with a heavy load, the greater the DGS output power, the less the effect on the voltage unbalance of the connected distribution feeder.

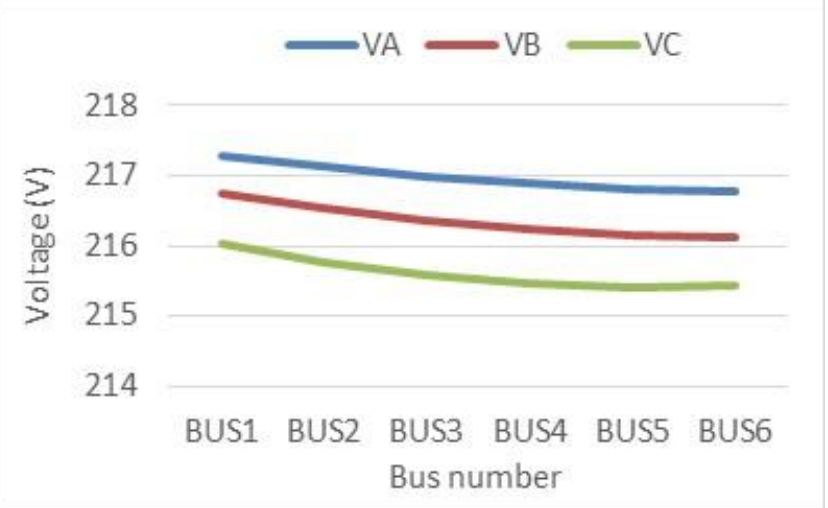

Fig. 11. The voltage profiles of the sample feeder in scenario S7.

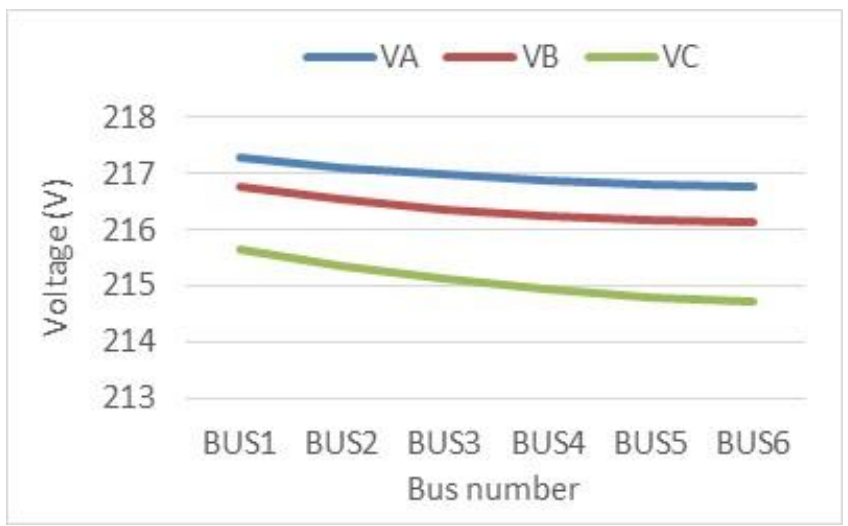

Fig. 12. The voltage profiles of the sample feeder in scenario S8. 


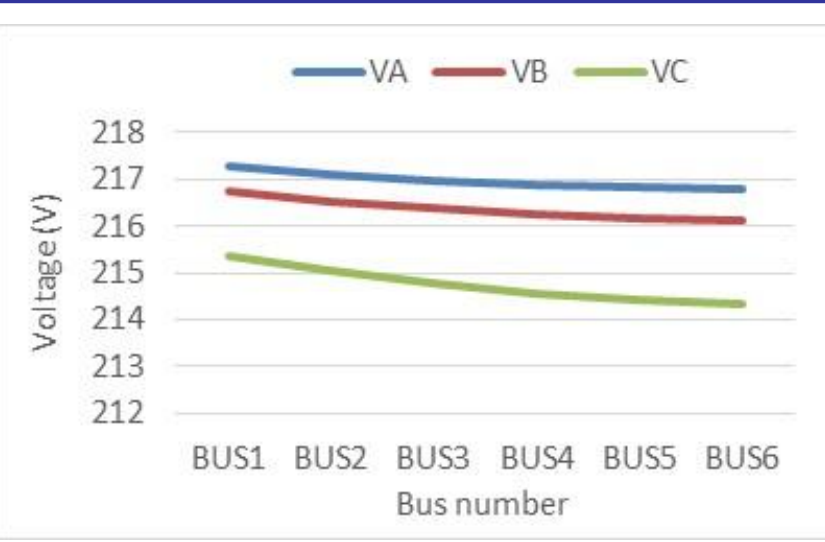

Fig. 13. The voltage profiles of the sample feeder in scenario S9.

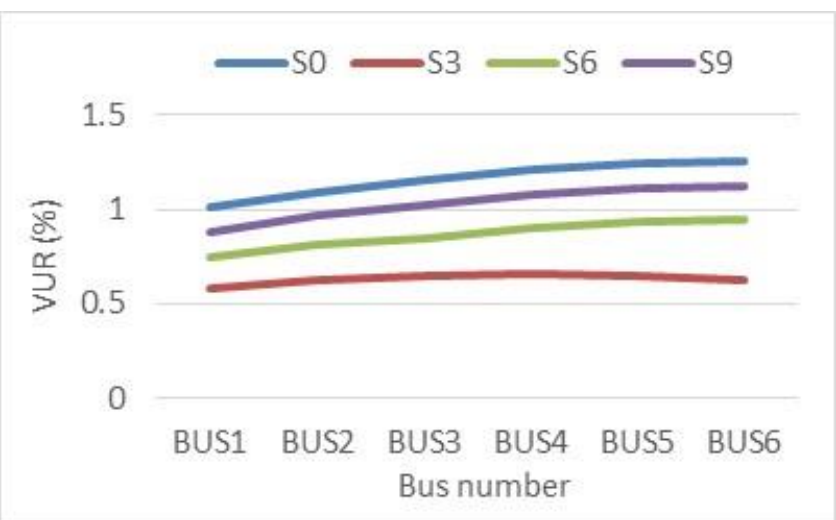

Fig. 14. The VURs of the sample feeder in scenario S0 and S7 to S9.

\section{CONCLUSIONS}

The voltage unbalance of a three-phase low-voltage distribution feeder with a DGS has been analyzed by this research. Simulation results shown in this paper has demonstrated that the interconnection of a DGS does affect the voltage unbalance of the connected three-phase lowvoltage distribution feeder. This effect may increase or decrease the degree of voltage unbalance, depending on the interconnection point, interconnection phase, and power generation of the DGS. In general, the closer the interconnection point of a DGS is to the end of the connected distribution feeder, the greater the effect of the distribution feeder's voltage unbalance. If a DGS interconnects to the phase with heavy load of a distribution feeder, its effect on the voltage unbalance of the distribution feeder will be less. In addition, the greater the power generation of a DGS, the greater the effect on the voltage unbalance of the connected distribution feeders. The application of DG is more and more today [8].The results shown in this paper can be used as a reference for power engineers to assist them in maintaining the power quality of their low-voltage distribution systems.

\section{ACKNOWLEDGMENT}

This research was founded by a grant provided by the Ministry of Science and Technology, Taiwan, R.O.C., under the grant number: MOST 107-2221-E-149-001.

\section{REFERENCES}

[1] I. David, F. Leon, and M. Barrie, Renewable Energy in Power Systems, John Wiley \& Sons, New Jersey, United States, 2019.

[2] H. R. Rainer, Sustainable Energy Policies for Europe: Towards 100\% Renewable Energy, CRC Press, Florida, United States, 2018.

[3] L. I. Dulăua, M. Abrudean, and D. Bică, "Effects of distributed generation on electric power systems," ELSEVIER Procedia Technology, vol. 12, pp. 681-686, 2014.

[4] K.Balamurugana, D. Srinivasana, and T. Reindl, "Effects of distributed generation on electric power systems," ELSEVIER Energy Procedia, vol. 25, pp. 93-100, 2012.

[5] S. H. Hashemi, M. H. Ashouian, and H. Pirpiran, "Impact of distributed generation on unbalanced distribution networks," $22^{\text {nd }}$ International Conference on Electricity Distribution, 2013, p. 1-4.

[6] D. Caples, S. Boljevic, and M. F. Conlon, "Impact of distributed generation on voltage profile in $38 \mathrm{kV}$ distribution system," $8^{\text {th }}$ International Conference on the European Energy Market, 2011, p. 1-5.

[7] L. I. Dulăua, M. Abrudean, and D. Bică, "Optimal location of a distributed generator for power losses improvemen," ELSEVIER Procedia Technology, vol. 22, pp. 734-739, 2016.

[8] P. Jayakumar, and P. Reji, "Modeling of power distribution feeder and analysis of small PV plant penetration in Kerala low voltage distribution system," International Conference on Cogeneration, Small Power Plants and District Energy, 2016, p. 1-4. 